\title{
Neutropenia occurrence and predictors of reduced chemotherapy delivery: results from the INC-EU prospective observational European neutropenia study
}

\author{
Ruth Pettengell • Matthias Schwenkglenks • \\ Robert Leonard • André Bosly • Robert Paridaens • \\ Manuel Constenla • Thomas D. Szucs • \\ Christian Jackisch • \\ Impact of Neutropenia in Chemotherapy-European \\ Study Group (INC-EU)
}

Received: 30 October 2007 / Accepted: 20 February 2008 /Published online: 20 March 2008

(C) The Author(s) 2008

\begin{abstract}
Goals of work Neutropenia is a life-threatening, doselimiting toxicity of many chemotherapy regimens. The goals of this study were to assess the incidence and risk of chemotherapy-induced neutropenia, febrile neutropenia (FN) and dose limitations in breast cancer and lymphoma patients undergoing chemotherapy in Europe.

Patients and methods Four hundred forty-four breast cancer and 305 lymphoma patients undergoing chemotherapy at 66 practices in five European countries participated in this prospective, observational study. Predictors of impaired
\end{abstract}

R. Pettengell $(\bowtie)$

Cellular and Molecular Medicine,

St. George's University of London,

Cranmer Terrace,

London SW17 0RE, UK

e-mail: rpetteng@sgul.ac.uk

M. Schwenkglenks · T. D. Szucs

European Centre of Pharmaceutical Medicine,

University of Basel,

c/o ECPM Executive Office, University Hospital,

CH-4031 Basel, Switzerland

M. Schwenkglenks

e-mail: m.schwenkglenks@unibas.ch

T. D. Szucs

e-mail: thomas.szucs@unibas.ch

\section{R. Leonard}

Hammersmith Hospital and Imperial College,

Du Cane Road,

London W12 0NN, UK

e-mail: BLeonard@hhnt.nhs.uk chemotherapy delivery were investigated using a logistic regression model.

Main results In breast cancer, FN incidence was low (6\%); however, grade 4 neutropenia was frequent (34\%). Lymphoma patients experienced higher incidences of FN (non-Hodgkin lymphoma (NHL) 22\%; Hodgkin lymphoma (HL) 15\%) and grade 4 neutropenia (NHL 54\%; HL 40\%). For both diseases, FN and grade 4 neutropenia were associated with low relative dose intensity (RDI). Multivariate regression models indicated that first cycle FN, age $\geq 65$ years and Eastern Co-operative Oncology Group $>1$ were associated with low RDI in breast

\footnotetext{
A. Bosly

Service d'Hématologie, Cliniques Universitaires UCL,

Avenue Dr. Gaston Therasse,

Godinne 5530, Belgium

e-mail: andre.bosly@sang.ucl.ac.be

R. Paridaens

Department of Medical Oncology,

University Hospital Gasthuisberg,

Herestraat 49,

Leuven 3000, Belgium

e-mail: robert.paridaens@uz.kuleuven.ac.be

M. Constenla

Servicio de Oncologia, Complexo Hospitalario de Pontevedra,

Pontevedra 36071, Spain

e-mail: mconstenla@ya.com

C. Jackisch

Department of Gynecology and Obstetrics, Klinikum Offenbach,

Starkenburgring 66,

Offenbach 63069, Germany

e-mail: christian.jackisch@klinikum-offenbach.de
} 
cancer and lymphoma, while colony-stimulating factor (CSF) primary prophylaxis appeared to be protective in lymphoma only. Primary CSF prophylaxis was provided to $9 \%$ of breast cancer, $28 \%$ of NHL and $19 \%$ of HL patients.

Conclusions Neutropenia and low RDI remain serious problems in both breast cancer and lymphoma populations undergoing chemotherapy. Several risk factors which can trigger reduced chemotherapy delivery were identified. These results can support physicians in identifying patients most at risk of receiving impaired chemotherapy delivery who would benefit from suitable preventive measures.

Keywords Breast cancer - Lymphoma . Neutropenia . Risk model $\cdot$ Relative dose intensity

\section{Introduction}

Myelosuppression represents the major dose-limiting toxicity of anti-cancer chemotherapy [10]. Chemotherapyinduced neutropenia (CIN) can lead to febrile neutropenia (FN), which requires immediate hospitalisation and treatment with antibiotics for patients with increased risk of lifethreatening infections $[8,10,24]$. The level of in-hospital mortality associated with patients who are hospitalised for $\mathrm{FN}$ is $9.5 \%$ on average and more than $21 \%$ for patients with co-morbidities [12].

Chemotherapy dose reductions and dose delays, as a result of $\mathrm{CIN}$ and $\mathrm{FN}$, can lead to reduced patient survival $[2-5,13-15,17]$. The risk of CIN and FN is particularly high for elderly patients $[1,29,33]$, which may account for a tendency to reduce chemotherapy treatment in this group $[1,15,29]$.

Despite the potential consequences of myelosuppression, myelotoxic chemotherapy remains central to the current standard of care for breast cancer and lymphoma patients. Over the past decade, breast cancer chemotherapy regimens based on cyclophosphamide, methotrexate and fluorouracil (CMF) have been superseded by more efficacious, but still myelotoxic, anthracycline-based regimens, such as fluorouracil, epirubicin and cyclophosphamide (FEC) [1, 30, 34]. Increased myelotoxicity might occur due to the adoption of some taxane-based therapies, such as docetaxel, doxorubicin and cyclophosphamide (TAC) [1, 20], which was recently recommended in treatment guidelines for early node-positive breast cancer [23].

For patients with aggressive non-Hodgkin lymphoma (NHL), combination therapy with cyclophosphamide, doxorubicin, vincristine and prednisone (CHOP) has been the standard treatment since its development in the 1970s [31]. The recent addition of rituximab to the regimen has further improved patient outcomes [6, 31], although both regimens carry a significant risk of neutropenia $[1,19$,
33]. Dose-dense CHOP (CHOP-14; administered every 14 days, supported with colony-stimulating factor) has been shown to improve patient survival compared with the 21-day regimen in both young and old patients [26, 27]. The most commonly used chemotherapy regimens for patients with Hodgkin lymphoma (HL) are associated with a lower risk of neutropenia; doxorubicin, bleomycin, vinblastine and dacarbazine (ABVD) or Stanford V (mechlorethamine, doxorubicin, etoposide, vincristine, vinblastine, bleomycin and prednisone) are widely used for early-stage disease, whilst bleomycin, etoposide, doxorubicin, cyclophosphamide, vincristine, procarbazine and prednisone (BEACOPP) is an additional option for advanced-stage disease $[11,21]$.

Primary prophylaxis with colony-stimulating factors (CSFs) reduces the risk of FN $[1,7,22,33]$ and related chemotherapy dose reductions [25]. Therefore, a major treatment goal is to identify patients most at risk of developing neutropenia and its consequences before they begin their chemotherapy treatment [18].

The Impact of Neutropenia in Chemotherapy-European (INC-EU) Study Group has pioneered this work within Europe, with the recent publication of a multi-national retrospective study addressing the incidence and risk factors of dose delays, dose reductions and hospitalisations related to neutropenia induced by adjuvant breast cancer chemotherapy [30]. Parallel retrospective studies in the US have resulted in similar advances for breast cancer and lymphoma patients $[15,17]$. Although these studies are clearly informative, retrospective data are limited by centrespecific deficits and differences in data availability.

The present paper presents results from a prospective study; the INC-EU Prospective Observational European Neutropenia Study was conducted to assess the incidence and predictors of grade 3-4 neutropenia, FN and reduced chemotherapy administration for breast cancer and lymphoma patients undergoing chemotherapy in European community practices. This paper reports the incidences of $\mathrm{CIN}, \mathrm{FN}$ and related hospitalisations in these patient groups, as well as patterns of CSF use and chemotherapy dose limitations. A logistic regression analysis of impaired chemotherapy delivery is also presented. Work on regression models of FN occurrence is ongoing.

\section{Patients and methods}

Study design and patient selection

This prospective study was conducted in 66 centres in Belgium, France, Germany, Spain and the UK. Ethical approval was obtained for all centres and all participants provided their informed consent. The design was observa- 
tional, and treatment was as per normal institutional clinical practice with the exception of a complete blood count at the expected (protocol defined) absolute neutrophil count (ANC) nadir in cycle 1 . Centres were required to record all blood counts taken during each patient's chemotherapy treatment.

Patients with a histologically confirmed diagnosis of malignancy were eligible for inclusion: Breast cancer patients requiring adjuvant or neo-adjuvant chemotherapy were accrued from the full range of stages I to III, fitting the primary tumour, nodes and metastasis classification of $\mathrm{T} 0$ 3 , N 0-2, M 0 . Stage 4 breast cancer patients were not included because these patients are often treated with less aggressive regimens with the intent of prolonging or improving quality of life, rather than cure. Lymphoma patients with $\mathrm{HL}$ stage $\mathrm{I}_{\mathrm{B}}-\mathrm{IV}$ or with $\mathrm{NHL}$ with an International Prognostic Index of 0-3 needing chemotherapy were also eligible. Adult participants (age 18 or older, without upper age limit) had to start a new myelosuppressive chemotherapy regimen sequence with at least four cycles planned. Prior or concurrent radiation therapy was allowed.
Key exclusion criteria were: active infection within $72 \mathrm{~h}$ prior to start of chemotherapy, conditions causing neutropenia, malignant conditions with myeloid characteristics, use of antibody-based or cell-based immunotherapies (with the exception of rituximab), history of stem cell or bone marrow transplantation and concurrent participation in phase I or phase II trials. Concomitant treatments deemed necessary to provide adequate supportive care were permitted. Patients were observed until the end of their chemotherapy regimen. Non-completion of planned chemotherapy regimens did not lead to exclusion from the study.

The primary endpoint was the incidence of grade 3 $\left(\mathrm{ANC}<1.0 \times 10^{9} / \mathrm{L}\right)$ and grade 4 neutropenia $(\mathrm{ANC}<0.5 \times$ $\left.10^{9} / \mathrm{L}\right)$. Secondary endpoints included incidence of: $\mathrm{FN}$ (grade 4 neutropenia and temperature $\geq 38^{\circ} \mathrm{C}$ ), chemotherapy cycle delays or dose reductions, relative dose intensity (RDI), neutropenia-related hospitalisations and patterns of CSF use.

Dose reductions were defined as a reduction of $\geq 10 \%$ of planned dose of at least one drug in at least one cycle; dose delays were defined as a delay of $\geq 4$ days in at least one cycle. RDI was defined as the ratio of the drug dose

Table 1 Patient and disease characteristics of breast cancer and lymphoma patients

\begin{tabular}{|c|c|c|c|c|}
\hline \multicolumn{2}{|l|}{ Characteristic } & Breast cancer $(N=444)$ & NHL $(N=240)$ & $\mathrm{HL}(N=65)$ \\
\hline \multicolumn{2}{|l|}{ Age, years; mean \pm SD (range) } & $53.5 \pm 10.2(27-81)$ & $63.2 \pm 12.9(17-90)$ & $39.2 \pm 17.5(18-79)$ \\
\hline \multicolumn{2}{|l|}{ Female gender, $n(\%)$} & $444(100)$ & $105(43.8)$ & $28(43.1)$ \\
\hline \multicolumn{2}{|c|}{ Oestrogen receptor status positive, $n(\%)$} & $297\left(67.4^{\mathrm{a}}\right)$ & - & - \\
\hline \multirow[t]{4}{*}{ HER2/Neu status, $n(\%)$} & 0 & $199\left(53.1^{\mathrm{b}}\right)$ & - & - \\
\hline & $1+$ & $54\left(14.4^{\mathrm{b}}\right)$ & & \\
\hline & $2+$ & $40\left(10.7^{\mathrm{b}}\right)$ & & \\
\hline & $3+$ & $82\left(21.9^{\mathrm{b}}\right)$ & & \\
\hline \multirow[t]{3}{*}{ Disease stage at inclusion, $n(\%)$} & I & $109\left(24.9^{c}\right)$ & - & - \\
\hline & II & $241\left(55.0^{\mathrm{c}}\right)$ & & \\
\hline & III & $88\left(20.1^{\mathrm{c}}\right)$ & & \\
\hline \multirow[t]{4}{*}{ Ann Arbor staging, $n(\%)$} & I & - & $42\left(17.7^{\mathrm{d}}\right)$ & $6(9.2)$ \\
\hline & II & & $62\left(26.2^{\mathrm{d}}\right)$ & $34(52.3)$ \\
\hline & III & & $39\left(16.5^{\mathrm{d}}\right)$ & $12(18.5)$ \\
\hline & IV & & $94\left(39.7^{\mathrm{d}}\right)$ & $13(20.0)$ \\
\hline \multicolumn{2}{|l|}{ B symptoms, $n(\%)$} & - & $113\left(47.7^{\mathrm{d}}\right)$ & $36(55.4)$ \\
\hline \multirow[t]{3}{*}{ IPI index, $n(\%)$} & low $(0-1)$ & - & $75\left(31.7^{\mathrm{d}}\right)$ & - \\
\hline & intermediate $(2-3)$ & & $132\left(55.7^{\mathrm{d}}\right)$ & \\
\hline & high $(\geq 4)$ & & $30\left(12.7^{\mathrm{d}}\right)$ & \\
\hline \multirow{2}{*}{\multicolumn{2}{|c|}{ No. of co-morbidities (mean $\pm \mathrm{SD}$, range) }} & $1.6 \pm 2.1$ & $2.1 \pm 2.1$ & $0.9 \pm 1.3$ \\
\hline & & $0-11$ & $0-11$ & $0-6$ \\
\hline \multicolumn{2}{|l|}{ Cardiovascular co-morbidity, $n(\%)$} & $95(21.4)$ & $65(27.1)$ & $8(12.3)$ \\
\hline \multicolumn{2}{|l|}{ Renal co-morbidity, $n(\%)$} & $13(2.9)$ & $16(6.7)$ & $1(1.5)$ \\
\hline
\end{tabular}

NHL Non-Hodgkin lymphoma, HL Hodgkin lymphoma, HER2 human epidermal growth factor receptor 2, IPI International Prognostic Index a $n=441$ due to missing values

${ }^{\mathrm{b}} n=375$ due to missing values

${ }^{\mathrm{c}} n=438$ due to missing values

${ }^{\mathrm{d}} n=237$ due to missing values 
actually administered in the actual time, over the planned dose in the planned time. Drug-specific RDIs obtained for each anti-malignant drug were averaged across each component of the chemotherapy regimen and across all planned chemotherapy cycles, regardless of whether they were administered or not. Corticosteroids and immunotherapeutic agents, including rituximab, were disregarded for RDI calculations. Low RDI was defined as $\mathrm{RDI} \leq 85 \%$. Hospitalisations were classified as neutropenia-related or not. CSF use was defined as primary prophylaxis (CSF use in the first cycle before a documented grade 3-4 CIN occurred or denoted as primary prophylaxis by site) or other use (incorporating CSF prophylaxis in cycles other than the first and CSF use in treatment).

\section{Statistical methods}

Assuming a dropout rate of $10 \%, 450$ breast cancer patients and 300 lymphoma patients were required to allow accurate estimation of the incidence of grade 3-4 CIN, with a $95 \%$ confidence interval (CI) width of $\pm 6 \%$ for each patient group (assuming an incidence rate of $20-30 \%$ for breast cancer and $40-60 \%$ for lymphoma patients) and for detecting relationships between various covariates and the incidence of neutropenia with $90 \%$ statistical power (assuming an underlying odds ratio of 2.25). Data were summarised using descriptive statistics. Preparatory univariate testing and subsequent multivariate logistic regression, using generalised-estimation-equations-based robust standard errors to allow for clustering by study centre, were used to assess predictors of low RDI, separately for breast cancer and lymphoma patients.

Covariates assessed for their relationship with low RDI included demographic information, patient and disease characteristics, co-morbidities (number and type), baseline laboratory data (including blood counts and constituent biochemical data), planned and actual treatment characteristics and neutropenic events. Assumed direct correlates of RDI were not used as covariates.

All tests were two-sided at the 5\% significance level. Two-sided 95\% CIs are shown, except where otherwise stated. CI calculation for binary variables assumed a binomial distribution. Statistical analyses were performed using the STATA $^{\circledR}$ version 9 statistical package.

\section{Results}

Patient characteristics

A total of 759 patients were enrolled between January 2004 and May 2005, of whom ten were not evaluable due to
Table 2 Treatment characteristics for breast cancer patients

\begin{tabular}{|c|c|c|c|c|}
\hline Regimen group ${ }^{\mathrm{a}}$ & Number & $\begin{array}{l}\text { Distribution } \\
\%\end{array}$ & $\begin{array}{l}\text { Primary CSF } \\
\text { prophylaxis } \\
\%^{\mathrm{c}}(n)\end{array}$ & $\begin{array}{l}\text { Other } \\
\text { CSF use } \\
\%^{\mathrm{c}}(n)\end{array}$ \\
\hline Total & 444 & 100 & $9.3^{\mathrm{d}}(41)$ & $24.4^{\mathrm{d}}(108)$ \\
\hline $\begin{array}{l}\text { Anthracycline } \\
\text { based }\end{array}$ & 312 & 70.3 & $4.5^{\mathrm{d}}(14)$ & $23.2^{\mathrm{d}}(72)$ \\
\hline $\mathrm{AC}$ & 74 & 16.7 & $1.4^{\mathrm{d}}(1)$ & $5.5^{\mathrm{d}}(4)$ \\
\hline $\mathrm{EC}$ & 38 & 8.6 & $10.5(4)$ & $31.6(12)$ \\
\hline FAC & 11 & 2.5 & $0(0)$ & $0(0)$ \\
\hline FEC & 152 & 34.2 & $6^{\mathrm{d}}(9)$ & $31.1^{\mathrm{d}}(47)$ \\
\hline E-CMF & 34 & 7.7 & $0(0)$ & $23.5(8)$ \\
\hline Other & 3 & 0.7 & $0(0)$ & $33.3(1)$ \\
\hline $\begin{array}{l}\text { Anthracycline } \\
\text { and taxane } \\
\text { containing }\end{array}$ & 112 & 25.2 & $22.3(25)$ & $31.3(35)$ \\
\hline $\begin{array}{l}\text { Sequential } \\
\text { starting } \\
\text { with an } \\
\text { anthracycline- } \\
\text { based regimen } \\
\text { and followed } \\
\text { by a taxane }\end{array}$ & 87 & 19.6 & $12.6(11)$ & $33.3(29)$ \\
\hline TAC & 17 & 3.8 & $70.6(12)$ & $11.8(2)$ \\
\hline $\begin{array}{l}\text { Other immediate } \\
\text { anthracycline-- } \\
\text { taxane } \\
\text { combinations }\end{array}$ & 8 & 1.8 & $25.0(2)$ & $50.0(4)$ \\
\hline Taxane-based & 2 & 0.5 & $0(0)$ & $0(0)$ \\
\hline $\mathrm{CMF}$ & 18 & 4.1 & $11.1(2)$ & $5.6(1)$ \\
\hline
\end{tabular}

$C S F$ Colony-stimulating factor, $A C$ adriamycin (doxorubicin) and cyclophosphamide, $E C$ epirubicin and cyclophosphamide, FAC 5fluorouracil, adriamycin (doxorubicin) and cyclophosphamide, $F E C$ 5-fluorouracil, epirubicin and cyclophosphamide, E-CMF epirubicin, cyclophosphamide, methotrexate and 5-fluorouracil; TAC taxotere (docetaxel), adriamycin (doxorubicin) and cyclophosphamide; $C M F$ cyclophosphamide, methotrexate and 5-fluorouracil

${ }^{\text {a }}$ Cycle length was 3 weeks for the majority of cases. AC: mostly doxorubicin $60 \mathrm{mg} / \mathrm{m}^{2}$; cyclophosphamide $600 \mathrm{mg} / \mathrm{m}^{2}$. EC: mostly epirubicin $90 \mathrm{mg} / \mathrm{m}^{2}$; cyclophosphamide $600 \mathrm{mg} / \mathrm{m}^{2}$. FEC: mostly 5fluorouracil $500-600 \mathrm{mg} / \mathrm{m}^{2}$; epirubicin $100 \mathrm{mg} / \mathrm{m}^{2}$; cyclophosphamide $500-600 \mathrm{mg} / \mathrm{m}^{2}$; cycle length of 4 weeks with drug administrations on cycle days 1 and 8 used in 11 cases. E-CMF: mostly epirubicin $100 \mathrm{mg} / \mathrm{m}^{2}$ followed by classical four weekly CMF, oral or ivbased. Sequential regimens composed of an anthracycline-based regimen and a taxane: first part mostly AC, EC or FEC; second part mostly docetaxel $100 \mathrm{mg} / \mathrm{m}^{2}$ or paclitaxel $175 \mathrm{mg} / \mathrm{m}^{2}$. TAC: docetaxel $75 \mathrm{mg} / \mathrm{m}^{2}$; doxorubicin $50 \mathrm{mg} / \mathrm{m}^{2}$; cyclophosphamide $500 \mathrm{mg} / \mathrm{m}^{2}$. CMF: classical four weekly CMF, oral or iv-based.

${ }^{\mathrm{b}}$ Other colony-stimulating factor (CSF) use: secondary prophylaxis or treatment.

${ }^{\mathrm{c}}$ Denominator values for calculations are the regimen $\mathrm{n}$-values in column 2, except where indicated.

${ }^{\mathrm{d}}$ Denominator $n$-value $=442$ (total) and 310 (anthracycline based); 73 (AC); 151 (FEC) due to missing values. 
Table 3 Treatment characteristics for lymphoma patients

\begin{tabular}{|c|c|c|c|c|c|}
\hline Regimen group & Number & Distribution (\%) & $\begin{array}{l}\text { Primary CSF } \\
\text { prophylaxis } \%^{\mathrm{c}}(n)\end{array}$ & $\begin{array}{l}\text { Other CSF } \\
\text { use }{ }^{\text {a } \%{ }^{c}(n)}\end{array}$ & $\begin{array}{l}\text { Rituximab } \\
\text { administration } \%{ }^{\mathrm{c}}(n)\end{array}$ \\
\hline \multicolumn{6}{|l|}{ NHL } \\
\hline Total & 240 & 100 & $27.5(66)$ & $28.8(69)$ & 81.7 (196) \\
\hline CHOP-21-like ${ }^{b}$ & 178 & 74.2 & $12.4(22)$ & $34.3(61)$ & 86.5 (154) \\
\hline CHOP-14-like & 41 & 17.1 & $75.6(31)$ & $9.8(4)$ & $65.9(27)$ \\
\hline ACVBP like & 9 & 3.8 & $55.6(5)$ & $33.3(3)$ & $77.8(7)$ \\
\hline NHL other & 12 & 5.0 & $66.7(8)$ & $8.3(1)$ & $66.7(8)$ \\
\hline \multicolumn{6}{|l|}{$\mathrm{HL}$} \\
\hline Total & 65 & 100 & $18.5(12)$ & $36.9(24)$ & - \\
\hline ABVD like & 47 & 72.3 & $8.5(4)$ & $44.7(21)$ & - \\
\hline Hodgkin other & 18 & 27.7 & $44.4(8)$ & $16.7(3)$ & - \\
\hline Stanford V & 5 & 7.7 & $20.0(1)$ & $0(0)$ & - \\
\hline BEACOPP-like & 8 & 12.3 & $62.5(5)$ & $25.0(2)$ & - \\
\hline ChlVPP-like & 5 & 7.7 & $40.0(2)$ & $20.0(1)$ & - \\
\hline
\end{tabular}

CSF Colony-stimulating factor, $C H O P$ cyclophosphamide, hydroxydaunomycin (doxorubicin), oncovin (vincristine) and prednisone, $A C V B P$ adriamycin (doxorubicin), cyclophosphamide, vindesine, bleomycin and prednisone, $N H L$ non-Hodgkin lymphoma, $H L$ Hodgkin lymphoma, $A B V D$ adriamycin (doxorubicin), bleomycin, vinblastine and dacarbazine, BEACOPP bleomycin, etoposide, adriamycin (doxorubicin), cyclophosphamide, oncovin (vincristine), procarbazine and prednisone, ChlVPP chlorambucil, vinblastine, procarbazine and prednisone

${ }^{a}$ Other CSF use, non-primary prophylaxis or treatment.

${ }^{\mathrm{b}}$ Includes six patients with a cycle length of 28 days.

${ }^{\mathrm{c}}$ Denominator values for percentage calculations are the regimen $n$-values in column 2 .

Table 4 Occurrence of neutropenia and FN by regimen for breast cancer and lymphoma patients

\begin{tabular}{|c|c|c|c|c|c|}
\hline Regimen & Number & $\begin{array}{l}\text { Any grade } 4 \text { neutropenia } \\
\%^{\mathrm{a}}(95 \% \mathrm{CI})\end{array}$ & $\begin{array}{l}\text { Any FN } \%{ }^{a} \\
(95 \% \mathrm{CI})\end{array}$ & $\begin{array}{l}\text { First cycle grade } 4 \\
\text { neutropenia } \%^{\mathrm{a}}(95 \% \mathrm{CI})\end{array}$ & $\begin{array}{l}\text { First cycle FN \% } \\
(95 \% \mathrm{CI})\end{array}$ \\
\hline \multicolumn{6}{|l|}{ Breast cancer } \\
\hline Total & 444 & $34.4(30.0-39.0)^{\mathrm{b}}$ & $5.9(3.9-8.5)^{\mathrm{b}}$ & $24.4(20.5-28.7)^{\mathrm{b}}$ & $3.9(2.3-6.1)^{\mathrm{b}}$ \\
\hline Anthracycline based & 312 & $36.7(31.3-42.3)^{\mathrm{c}}$ & $6.4(4.0-9.8)^{\mathrm{c}}$ & $28.5(23.5-33.9)^{\mathrm{c}}$ & $4.2(2.3-7.1)^{\mathrm{c}}$ \\
\hline $\begin{array}{l}\text { Anthracycline and taxane } \\
\text { containing excluding TAC }\end{array}$ & 95 & $31.6(22.4-41.9)$ & $5.3(1.7-11.9)$ & $17.2(10.2-26.4)^{\mathrm{d}}$ & $3.2(0.7-9.0)$ \\
\hline TAC & 17 & $43.8(19.8-70.1)^{\mathrm{e}}$ & $5.9(0.1-28.7)$ & $18.8(4.0-45.6)^{\mathrm{e}}$ & $5.9(0.1-28.7)$ \\
\hline $\mathrm{CMF}$ & 18 & $5.6(0.1-27.3)$ & $0.0(0.0-18.5)^{\mathrm{g}}$ & $0.0(0.0-18.5)^{\mathrm{f}, \mathrm{g}}$ & $0.0(0.0-19.5)^{\mathrm{f}, \mathrm{g}}$ \\
\hline \multicolumn{6}{|l|}{ NHL } \\
\hline Total & 240 & $53.8(47.2-60.2)$ & $22.1(17.0-27.9)$ & $34.6(28.6-41.0)$ & $8.9(5.5-13.1)$ \\
\hline CHOP-21 like & 178 & $53.4(45.8-60.9)$ & $21.9(16.1-28.7)$ & $34.8(27.9-42.3)$ & $9.6(5.7-14.9)$ \\
\hline CHOP-14 like & 41 & $48.8(32.9-64.9)$ & $17.1(7.2-32.1)$ & $24.4(12.4-40.3)$ & $2.4(0.1-12.9)$ \\
\hline ACVBP like & 9 & $88.9(51.8-99.7)$ & $44.4(13.7-78.8)$ & $77.8(40.0-97.2)$ & $0.0(0.0-33.6)^{\mathrm{g}}$ \\
\hline NHL other & 12 & $50.0(21.1-78.9)$ & $25.0(5.5-57.2)$ & $33.3(9.9-65.1)$ & $25.0(5.5-57.2)^{\mathrm{d}}$ \\
\hline \multicolumn{6}{|l|}{ HL } \\
\hline Total & 65 & $40.0(28.0-52.9)$ & $15.4(7.6-26.5)$ & $24.6(14.8-36.9)$ & $6.2(1.7-15.0)$ \\
\hline ABVD like & 47 & $34.0(20.9-49.3)$ & $14.9(6.2-28.3)$ & $21.3(10.7-35.7)$ & $8.5(2.4-20.4)$ \\
\hline HL other & 18 & $55.6(30.8-78.5)$ & $16.7(3.6-41.4)$ & $33.3(13.3-59.0)$ & $0.0(0.0-18.5)^{\mathrm{d}}$ \\
\hline
\end{tabular}

FN Febrile neutropenia, TAC taxotere (docetaxel), adriamycin (doxorubicin) and cyclophosphamide, $C M F$ cyclophosphamide, methotrexate and 5-fluorouracil, NHL non-Hodgkin lymphoma, CHOP cyclophosphamide, hydroxydaunomycin (doxorubicin), oncovin (vincristine) and prednisone, $A C V B P$ adriamycin (doxorubicin), cyclophosphamide, vindesine, bleomycin and prednisone, $H L$ Hodgkin lymphoma, $A B V D$ adriamycin (doxorubicin), bleomycin, vinblastine and dacarbazine; $C I N$ chemotherapy-induced neutropenia

${ }^{a}$ Denominator values are regimen $n$-values except where indicated.

${ }^{\mathrm{b}}$ Denominator $n$-value $=442$ (any grade IV CIN); 441 (any FN, cycle $1 \mathrm{FN}$ ); 438 (cycle 1 grade IV CIN) due to missing values.

${ }^{\mathrm{c}}$ Denominator $n$-value $=311$ (any grade IV CIN); 310 (any FN, cycle $1 \mathrm{FN}$ ); 309 (cycle 1 grade IV CIN) due to missing values.

${ }^{\mathrm{d}}$ Denominator $n$-value $=93$ due to missing values.

${ }^{\mathrm{e}}$ Denominator $n$-value $=16$ due to a missing value

${ }^{\mathrm{f}}$ Denominator $n$-value $=17$ due to a missing value.

${ }^{g}$ One-sided $97.5 \%$ CI. 
almost complete lack of data. Eight of these ten patients were found to be ineligible. The distribution of the remaining 749 patients was: Belgium, 105 (14\%); France, 94 (13\%); Germany, 306 (41\%); Spain, 38 (5\%); and UK, 206 (28\%). Patient split by diagnosis was; breast cancer 444 (59\%); NHL 240 (32\%); HL 65 (9\%). Four NHL patients were classified as relapsed leukaemias. Patient and disease characteristics are summarised in Table 1.

\section{Treatment characteristics}

Over $70 \%$ of breast cancer patients received anthracyclinebased regimens, with FEC being the most frequent regimen (34\%), followed by anthracycline-taxane regimens $(25 \%$; Table 2). Non-anthracycline, taxane-based and CMF regimens were used infrequently. The planned number of chemotherapy cycles (mean \pm SD) was $5.5 \pm 1.1$ in those receiving non-sequential regimens and $7.9 \pm 0.8$ in those receiving sequential regimens. Cycle length was usually 3 weeks. Primary prophylaxis with CSFs was generally low at $9 \%$, although more than $70 \%$ of patients receiving TAC also received primary CSF prophylaxis (Table 2).

CHOP-21 and CHOP-14 regimens were used in $74 \%$ and $17 \%$ of NHL patients, respectively (Table 3). Ritux- imab use was high, averaging $82 \%$ across all NHL regimens. The planned number of chemotherapy cycles (mean $\pm \mathrm{SD}$ ) was $6.2 \pm 1.5$ and cycle length was usually 3 weeks. Twelve per cent of patients receiving CHOP-21 regimens and $76 \%$ of patients on the dose-dense CHOP-14 regimens received prophylactic CSF support from the first cycle (Table 3).

The majority of HL patients received ABVD-like regimens $(72 \%)$, with BEACOPP being the second most common category (12\%; Table 3$)$. The planned number of chemotherapy cycles (mean \pm SD) was $5.4 \pm 1.7$ and cycle length was usually 4 weeks. Primary prophylactic CSF use for HL patients averaged at $19 \%$, ranging from $9 \%$ for ABVD-like regimens to $63 \%$ for BEACOPP-like regimens.

\section{Incidence of neutropenia and FN}

Table 4 details the incidence of neutropenia and FN across all cycles of chemotherapy and during the first cycle. Grade 3-4 neutropenia occurred in $64 \%$ of breast cancer patients, with $34 \%$ experiencing grade $4 \mathrm{CIN}$; in contrast, FN occurred in only $6 \%$ of breast cancer patients. The incidence of grade 3-4 neutropenia was $72 \%$ for NHL patients (54\% experienced grade 4$)$ and $75 \%$ for $\mathrm{HL}$

Table 5 Occurrence of chemotherapy dose limitations in breast cancer and lymphoma patients

\begin{tabular}{|c|c|c|c|c|}
\hline Regimen group & $\mathrm{N}$ & $\begin{array}{l}\text { Dose delay } \geq 4 \text { days }^{\mathrm{a}} \%^{\mathrm{d}} \\
(95 \% \mathrm{CI})\end{array}$ & $\begin{array}{l}\text { Dose reduction } \geq 10 \%{ }^{\mathrm{b}} \%^{\mathrm{d}} \\
(95 \% \mathrm{CI})\end{array}$ & $\begin{array}{l}\mathrm{RDI} \leq 85 \%^{\mathrm{c}} \%^{\mathrm{d}} \\
(95 \% \mathrm{CI})\end{array}$ \\
\hline \multicolumn{5}{|l|}{ Breast cancer } \\
\hline Total & 444 & $35.1(30.7-39.8)$ & $14.2(11.1-17.8)$ & $21.4(17.7-25.5)$ \\
\hline Anthracycline based & 312 & $36.5(31.2-42.1)$ & $12.2(8.8-16.3)$ & $22.4(17.9-27.5)$ \\
\hline $\begin{array}{l}\text { Anthracycline- and taxane } \\
\text { containing excluding TAC }\end{array}$ & 95 & $32.6(23.4-43.0)$ & $20.0(12.5-29.5)$ & $16.8(9.9-25.9)$ \\
\hline TAC & 17 & $29.4(10.3-56.0)$ & $17.6(3.8-43.4)$ & $29.4(10.3-56.0)$ \\
\hline $\mathrm{CMF}$ & 18 & $22.2(6.4-47.6)$ & $11.1(1.4-34.7)$ & $11.1(1.4-34.7)$ \\
\hline \multicolumn{5}{|l|}{ NHL } \\
\hline Total & 240 & $45.8(39.4-52.4)$ & $33.3(27.4-39.7)$ & $36.3(30.2-42.7)$ \\
\hline CHOP-like three weekly & 178 & $46.1(38.6-53.7)$ & $35.4(28.4-42.9)$ & $33.2(26.3-40.6)$ \\
\hline CHOP-like two weekly & 41 & $46.3(30.7-62.6)$ & $24.4(12.4-40.3)$ & $43.9(28.5-60.3)$ \\
\hline ACVBP like & 9 & $44.4(13.7-78.8)$ & $44.4(13.7-78.8)$ & $55.6(21.2-86.3)$ \\
\hline NHL other & 12 & $41.7(15.2-72.3)$ & $25.0(5.5-57.2)$ & $41.7(15.2-72.3)$ \\
\hline \multicolumn{5}{|l|}{ HL } \\
\hline Total & 65 & $60.0(47.1-72.0)$ & $46.2(33.7-59.0)$ & $32.3(21.2-45.1)$ \\
\hline ABVD like & 47 & $66.0(50.7-79.1)$ & $36.2(22.7-51.5)$ & $29.8(17.3-44.9)$ \\
\hline Other & 18 & $44.4(21.5-69.2)$ & $72.2(46.5-90.3)$ & $38.9(17.3-64.3)$ \\
\hline
\end{tabular}

CI Confidence interval, RDI relative dose intensity; TAC taxotere (docetaxel), adriamycin (doxorubicin) and cyclophosphamide; $C M F$ cyclophosphamide, methotrexate and 5-fluorouracil, NHL non-Hodgkin lymphoma, CHOP cyclophosphamide, hydroxydaunomycin (doxorubicin), oncovin (vincristine) and prednisone; $A C V B P$ adriamycin (doxorubicin), cyclophosphamide, vindesine, bleomycin and prednisone; $H L$ Hodgkin lymphoma; $A B V D$ adriamycin (doxorubicin), bleomycin, vinblastine and dacarbazine

${ }^{\mathrm{a}}$ In at least one cycle.

${ }^{\mathrm{b}}$ In at least one anti-malignant drug and at least one cycle.

${ }^{\mathrm{c}} \mathrm{RDI}$ was corrected for planned but non-administered cycles.

${ }^{\mathrm{d}}$ Denominator values are regimen $n$-values. 
patients ( $40 \%$ experienced grade 4 ). FN occurred in $22 \%$ of patients with NHL and $15 \%$ of HL patients. For both breast cancer and lymphoma patients, a high proportion of neutropenic events occurred during the first cycle of chemotherapy. Neutropenia-related hospitalisations occurred in $18 \%$ of NHL patients, $14 \%$ of HL patients and $5 \%$ of breast cancer patients.

\section{Chemotherapy dose limitations}

Eighty-six per cent of breast cancer patients received their planned number of chemotherapy cycles. More than one in five patients experienced some form of dose limitation. Dose delays $\geq 4$ days occurred in $35 \%$ of patients, dose reductions of $\geq 10 \%$ occurred in $14 \%$ of patients and $21 \%$ of the breast cancer patients received $\mathrm{RDI} \leq 85 \%$ (Table 5 ). For lymphoma, $72 \%$ of NHL patients completed their planned treatment cycles; dose delays occurred in $46 \%$ of patients, dose reductions in $33 \%$ of patients and $36 \%$ of NHL patients received $\mathrm{RDI} \leq 85 \%$. In HL patients, $85 \%$ of whom completed their planned treatment cycles, dose delays occurred in $60 \%$ of patients, dose reductions in $46 \%$ and $\mathrm{RDI} \leq 85 \%$ occurred in $32 \%$ of patients (Table 5 ).

\section{Predictors of impaired chemotherapy delivery}

The occurrence of CIN and FN had an impact on chemotherapy delivery. Figure 1 shows the results of a univariate analysis of the effects of grade 4 neutropenia and FN on the proportion of breast cancer and NHL patients experiencing dose delays, dose reductions and low RDI. Both groups were more likely to experience a dose delay if they also experienced grade 4 neutropenia, compared to patients with no neutropenic events $(p<0.05$ and $p<0.01$, respectively). For breast cancer patients, dose reductions

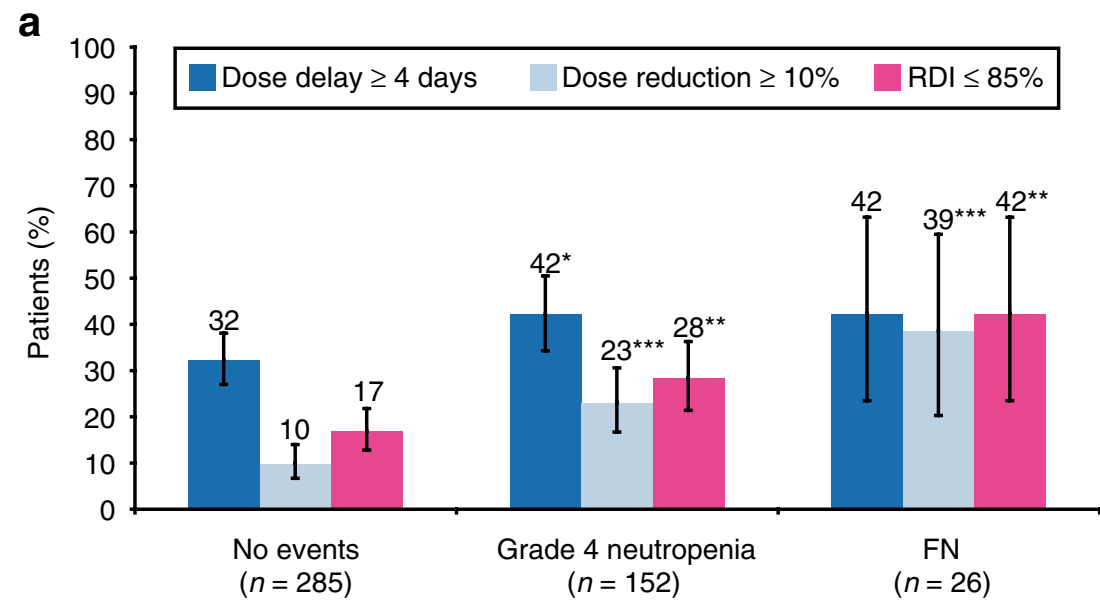

b

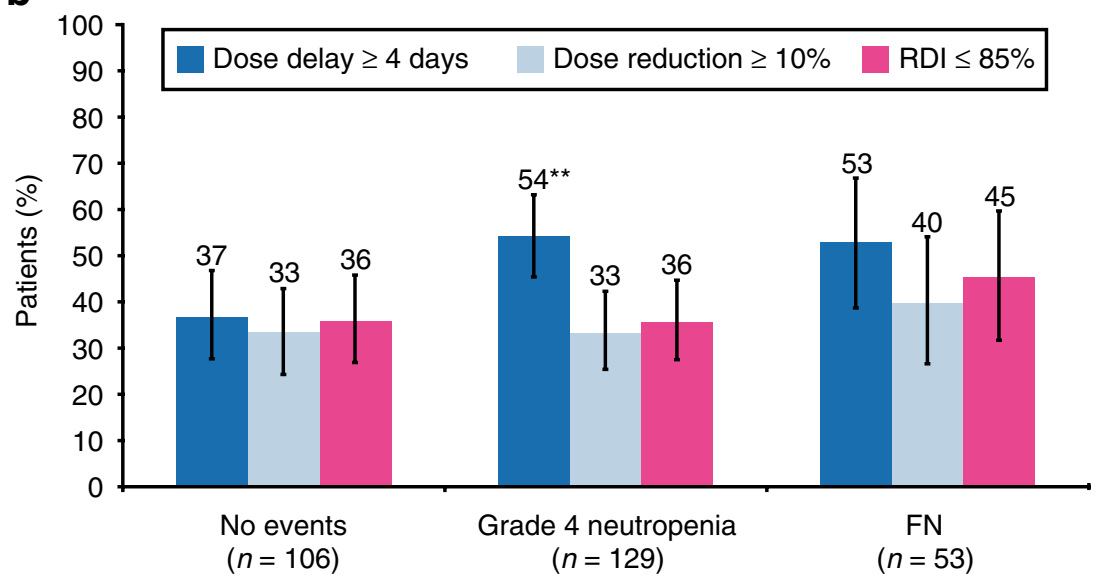

Fig. 1 Chemotherapy dose delays and reductions by neutropenic event. Data are shown for breast cancer patients (a) and NHL patients (b). Data represent univariate analyses and are not adjusted for

confounding factors. Error bars represent $95 \%$ CIs. $* p<0.05$, $* * p<$ $0.01, * * * p<0.001$, when compared to patients with no events 
and low RDI were more common in patients who experienced either grade 4 neutropenia or FN $(p<0.001$ and $p<0.01$, for dose reductions and $\mathrm{RDI} \leq 85 \%$, respectively). Overall, $28 \%$ of breast cancer patients and $36 \%$ of NHL patients who experienced grade 4 neutropenia received $\mathrm{RDI} \leq 85 \%$. For breast cancer and NHL patients who experienced $\mathrm{FN}, \mathrm{RDI} \leq 85 \%$ occurred in $42 \%$ and $45 \%$, respectively.

Multivariate logistic regression analysis identified three covariates that were significantly associated with low RDI occurrence in the breast cancer as well as lymphoma populations and showed similar effect sizes: ECOG status $>$ 1 , age $\geq 65$ years and cycle 1 FN occurrence (Table 6). When grade 4 neutropenia occurrence in cycle 1 was used as an alternative predictor to the cycle $1 \mathrm{FN}$ covariate, the resulting odds ratios were 1.94 (CI $1.22-3.07 ; p=0.005)$ in breast cancer and 1.37 (CI $0.80-2.35 ; p=0.258$ ) in lymphoma. Primary CSF prophylaxis had a strong protective effect for lymphoma. No such association was observed for breast cancer; however, it is important to consider this result in the context of the FN risk for each disease entity and factors driving provision of CSF (Table 4; see "Discussion"). Type of chemotherapy regimen was also significantly associated with low RDI occurrence in lymphoma.

\section{Discussion}

This study assessed the incidences of CIN and FN and their consequences for chemotherapy delivery in breast cancer and lymphoma patients undergoing chemotherapy in European academic and community practices between 2004 and 2006.

A significant proportion of FN and grade 4 neutropenia occurred in the first cycle of chemotherapy for the majority of regimens considered. This finding is consistent with reports from other studies $[9,16,28]$.

The incidence of $\mathrm{FN}$ for the most frequently used breast cancer regimens in European practice was low (6\%). However, grade 4 neutropenia occurred in a high proportion of patients (34\%) and significantly impacted upon chemotherapy delivery. Over $20 \%$ of breast cancer patients received $\mathrm{RDI} \leq 85 \%$, which has been shown to impact on survival [5].

Over $20 \%$ of NHL patients and $15 \%$ of HL patients developed $\mathrm{FN}$ at some point during the course of their chemotherapy treatment. Many lymphoma patients (54\% of NHL and $40 \%$ of HL patients) also experienced grade 4 neutropenia, which was associated with delays in planned chemotherapy treatment. Dose reductions were also frequent in this patient group; overall, $30 \%$ of lymphoma patients received $\mathrm{RDI} \leq 85 \%$. Recent results show that even reducing RDI to less than $90 \%$ can impact on survival in NHL patients receiving CHOP-21 [3].

A certain underestimation of neutropenia rates and, to a lesser extent, FN rates may have occurred because the frequency of blood counts was according to local institutional practice (apart from the protocol-specified blood count taken at cycle 1 nadir). However, the observed FN rates were generally in the range expected by current European Organisation for Research and Treatment of Cancer and American Society of Clinical Oncology guidelines $[1,33]$. The FN risk of patients treated with anthracycline-based regimens was $<10 \%$. Regimens with concomitant anthracyclines and taxanes that have a high $(>20 \%)$ generic FN risk, such as TAC, were appropriately supported by primary CSF prophylaxis in most cases. CHOP-21-like regimens were expected to have an intermediate to high risk of FN (17-50\%) [1]. In the present study, the overall FN rate for patients receiving CHOP-21-like regimens was $22 \%$ and primary CSF prophylaxis was provided to only $12 \%$ of these patients. This examination of the level of prophylactic CSF support provided to lymphoma patients, who frequently experienced CIN and FN, indicates that a shift in practice would be required if current European guidelines are to be followed [1].

Table 6 Multivariate models of low RDI occurrence

\begin{tabular}{|c|c|c|}
\hline $\mathrm{RDI} \leq 85 \%$ & $\begin{array}{l}\text { Breast cancer }{ }^{\mathrm{a}} \\
\text { OR }(95 \% \mathrm{CI}) \\
p \text {-value }\end{array}$ & $\begin{array}{l}\text { Lymphoma }^{\mathrm{b}} \\
\text { OR }(95 \% \mathrm{CI}) \\
p \text {-value }\end{array}$ \\
\hline Age $\geq 65$ years & $1.73(1.12-2.70), 0.014$ & $1.74(1.12-2.70), 0.013$ \\
\hline $\mathrm{ECOG}>1$ & 4.13 (1.39-12.22), 0.010 & $2.42(1.25-4.70), 0.009$ \\
\hline Cycle 1 FN & $3.68(1.55-8.73), 0.003$ & $2.27(0.94-5.51), 0.069$ \\
\hline $\begin{array}{r}\text { Primary CSF } \\
\text { prophylaxis }\end{array}$ & Ns & $0.46(0.23-0.93), 0.029$ \\
\hline Regimen & Ns & \\
\hline CHOP-14-like ${ }^{c}$ & & $2.12(0.85-5.27), 0.106$ \\
\hline ACVBP like & & $5.51(2.27-13.39),<0.001$ \\
\hline NHL other ${ }^{c}$ & & $2.17(0.58-8.06), 0.247$ \\
\hline ABVD like ${ }^{c}$ & & $1.12(0.59-2.13), 0.719$ \\
\hline Hodgkin other ${ }^{\mathrm{c}}$ & & $2.15(0.86-5.33), 0.100$ \\
\hline
\end{tabular}

$R D I$ Relative dose intensity, $O R$ odds ratio, $C I$ confidence interval, $E C O G$ Eastern Co-operative Oncology Group, $F N$ febrile neutropenia, $C S F$ colony-stimulating factor, $n s$ non-significant, $C H O P$ cyclophosphamide, hydroxydaunomycin (doxorubicin), oncovin (vincristine) and prednisone; $A C V B P$ adriamycin (doxorubicin), cyclophosphamide, vindesine, bleomycin and prednisone; $N H L$ non-Hodgkin lymphoma; $A B V D$ adriamycin (doxorubicin), bleomycin, vinblastine and dacarbazine

${ }^{\text {a }} N=437$ due to missing values. Pseudo $R^{2}=0.027$. Robust standard error estimates adjusted for 39 clusters (centres).

${ }^{\mathrm{b}} N=304$ due to missing values. Pseudo $R^{2}=0.056$. Robust standard error estimates adjusted for 39 clusters (centres).

${ }^{\mathrm{c}}$ Reference: CHOP-21-like chemotherapy. $p=0.008$ (Wald test based) for this set of parametres. 
The practice of responding to $\mathrm{FN}$ by delaying or reducing chemotherapy has potentially serious consequences for patients including reduced survival [2, 3, 5]. Therefore, clinicians need to be made aware of the factors that can trigger chemotherapy dose limitations. We have modelled the factors associated with low RDI and shown that age $\geq 65$ years, ECOG $>1$ and cycle $1 \mathrm{FN}$ are specific risk factors for low RDI in breast cancer as well as lymphoma populations. Our results are consistent with other risk models, as recently reviewed by Lyman et al. [18]. Age $\geq 65$ years has been identified as a risk factor for low RDI in both breast cancer $[15,19,32]$ and NHL patients [17, 19]. Poor performance status has been identified as a risk factor for low RDI in patients with NHL [17] and the present results extend this finding to patients with breast cancer. We also specifically identified cycle $1 \mathrm{FN}$ and cycle 1 grade 4 neutropenia as risk factors for low RDI, complementing the results of other studies [32]. The effect of these latter factors was stronger in the breast cancer population than in lymphoma where neutropenic events are more frequent and may be managed with greater routine. Further external validation of these findings is of importance.

Interestingly, in the regression models, a protective effect of primary CSF prophylaxis against low RDI was observed for lymphoma but not for breast cancer patients. This finding was unexpected and the most likely explanation is that most breast cancer patients received chemotherapy regimens with low FN risk, and primary CSF prophylaxis was only provided to those few patients who received highrisk regimens or was targeted to patients who did not require it. This selective use of CSF prophylaxis could not be represented in the model.

Choice of chemotherapy regimen is a key driver of adverse events including neutropenia and $\mathrm{FN}$ and therefore contributes to every patient's risk of low RDI. In this analysis, regimen type was a significant covariate in the lymphoma model but not in the breast cancer model. It appears that the breast cancer regimen types considered in this study had a similar potential to trigger low RDI, after modification by other factors (such as whether CSF prophylaxis was provided or not). In lymphoma, the set of covariates representing regimen types was statistically significant in its entirety and needed to be included in the model to avoid residual confounding. However, the individual coefficients were mostly non-significant and should be interpreted with great care.

The overall predictive ability of the low RDI models remained low, which is partially explained by a special characteristic. The factors identified here and in other published models of low RDI occurrence do not cause low RDI directly, they only influence clinical decision making, which is subject to substantial variation. Ulti- mately, low RDI is always a direct consequence of clinical decisions to dose delay or dose reduce (which are based on personal judgment and/or local institutional practice). Therefore, it would be difficult, and perhaps problematic, to construct clinical prediction rules for low RDI (while constructing prediction rules for other endpoints such as FN makes perfect sense). The contribution of low RDI models is to make clinicians aware of factors that often trigger decisions towards impaired chemotherapy delivery and thus, perhaps, to change clinical behaviours and improve patient management at both individual and institutional levels.

In sum, this prospective observational study provides information about the occurrence of CIN and FN in current European community practice and examines how neutropenic events and other factors impact upon chemotherapy delivery. The results indicate that neutropenia and impaired chemotherapy delivery remain serious problems in both breast cancer and lymphoma patient populations. Rather than acting to prevent, current clinical practice frequently delays or reduces chemotherapy, which may have severe long-term implications [2, 3, 5].

Acknowledgements The authors wish to thank Amgen (Europe) $\mathrm{GmbH}$, Zug, Switzerland, for supporting this work by an unrestricted, educational grant. For providing patient data, the authors would also like to thank J.C.A. Adansa, J.J.C. Hernandez, S. Al-Ismail, C. André, G.-A. Banat, A. Barnes, A.L. Barriuso, J.L. Bello, A. Biswas, A. Bols, A. Brownell, W. Brugger, R.O. Casasnovas, M. Clemens, R. Coleman, P. Colombat, N. Davidson, R. Depenbusch, H.G. Derigs, A. Engert, J.C. Espinosa, S. Ferrer, O. Fitoussi, B. Gaede, L. Garderet, B. Hancock, M. Hänel, A. Hasenburg, A. Hong, U. Karck, G. Köhler, A.W. Hutcheon, C. Lerchenmüller, R. Lipp, J.R.M. Lorenzo, K. McAdam, F. Majois, J.L. Mansi, M.G. Martinez, J. Mebis, N. Mounier, A.A. Munoz, A. O'Callaghan, M. Quigley, S. Rösel, C. Rudin, R. Schlag, G. Schlimok, M. Sandherr, P. Solal-Celigny, T. Steck, H. Tesch, D. Turner, X. Vallantin, J. Van Erps, E. Van Den Neste, A. Van Hoof, J.B. Vermorken, K. Verpoort, A. Wardley, M. Warm, E. Weidmann, J. Wimperis and W. Zeller. The authors wish to thank Dr L. Woodford and Dr R. Mackinlay from Medcept Ltd., Switzerland, who provided medical writing services on behalf of Amgen (Europe) GmbH.

Open Access This article is distributed under the terms of the Creative Commons Attribution Noncommercial License which permits any noncommercial use, distribution, and reproduction in any medium, provided the original author(s) and source are credited.

\section{References}

1. Aapro MS, Cameron DA, Pettengell R, Bohlius J, Crawford J, Ellis M, Kearney N, Lyman GH, Tjan-Heijnen VC, Walewski J, Weber DC, Zielinski C (2006) EORTC guidelines for the use of granulocyte-colony stimulating factor to reduce the incidence of chemotherapy-induced febrile neutropenia in adult patients with lymphomas and solid tumours. Eur J Cancer 42:24332453 
2. Bonadonna G, Valagussa P, Moliterni A, Zambetti M, Brambilla C (1995) Adjuvant cyclophosphamide, methotrexate, and fluorouracil in node-positive breast cancer: the results of 20 years of follow-up. N Engl J Med 332:901-906

3. Bosly A, Bron D, Van Hoof A, De Bock R, Berneman Z, Ferrant A, Kaufman L, Dauwe M, Verhoef G (2008) Achievement of optimal average relative dose intensity and correlation with survival in diffuse large B-cell lymphoma patients treated with CHOP. Ann Hematol, online advance access DOI 10.1007/ s00277-007-0399-y

4. Budman DR, Berry DA, Cirrincione CT, Henderson IC, Wood WC, Weiss RB, Ferree CR, Muss HB, Green MR, Norton L, Frei E3 (1998) Dose and dose intensity as determinants of outcome in the adjuvant treatment of breast cancer. The Cancer and Leukemia Group B. J Natl Cancer Inst 90:1205-1211

5. Chirivella I, Bermejo B, Insa A, Perez-Fidalgo A, Magro A, Rosello E, Garcia-Garre E, Martin P, Bosch A, Lluch A (2006) Impact of chemotherapy dose-related factors on survival in breast cancer patients treated with adjuvant anthracycline-based chemotherapy. J Clin Oncol 24:44s (Abs 668)

6. Coiffier B, Lepage E, Briere J, Herbrecht R, Tilly H, Bouabdallah R, Morel P, Van Den Neste E, Salles G, Gaulard P, Reyes F, Gisselbrecht C (2002) CHOP chemotherapy plus rituximab compared with CHOP alone in elderly patients with diffuse large-B-cell lymphoma. N Engl J Med 346:235-242

7. Crawford J, Ozer H, Stoller R, Johnson D, Lyman G, Tabbara I, Kris M, Grous J, Picozzi V, Rausch G et al (1991) Reduction by granulocyte colony-stimulating factor of fever and neutropenia induced by chemotherapy in patients with small-cell lung cancer. N Engl J Med 325:164-170

8. Crawford J, Dale DC, Lyman GH (2004) Chemotherapy-induced neutropenia: risks, consequences, and new directions for its management. Cancer 100:228-237

9. Crawford J, Wolff DA, Culakova E, Poniewierski MS, Selby C, Dale DC, Lyman GH (2004) First cycle risk of severe and febrile neutropenia in cancer patients receiving systemic chemotherapy: results from a prospective nationwide study. Blood 104:Abs 2210

10. Dale DC, McCarter GC, Crawford J, Lyman GH (2003) Myelotoxicity and dose intensity of chemotherapy: reporting practices from randomized clinical trials. J Natl Compr Canc Netw 1:440-454

11. Diehl V, Franklin J, Pfreundschuh M, Lathan B, Paulus U, Hasenclever D, Tesch H, Herrmann R, Dorken B, MullerHermelink HK, Duhmke E, Loeffler M (2003) Standard and increased-dose BEACOPP chemotherapy compared with COPPABVD for advanced Hodgkin's disease. N Engl J Med 348:23862395

12. Kuderer NM, Dale DC, Crawford J, Cosler LE, Lyman GH (2006) Mortality, morbidity, and cost associated with febrile neutropenia in adult cancer patients. Cancer 106:2258-2266

13. Kwak LW, Halpern J, Olshen RA, Horning SJ (1990) Prognostic significance of actual dose intensity in diffuse large-cell lymphoma: results of a tree-structured survival analysis. J Clin Oncol 8:963-977

14. Leonard RC, Miles D, Thomas R, Nussey F (2003) Impact of neutropenia on delivering planned adjuvant chemotherapy: UK audit of primary breast cancer patients. Br J Cancer 89:20622068

15. Lyman GH, Dale DC, Crawford J (2003) Incidence and predictors of low dose-intensity in adjuvant breast cancer chemotherapy: a nationwide study of community practices. J Clin Oncol 21:45244531

16. Lyman GH, Morrison VA, Dale DC, Crawford J, Delgado DJ, Fridman M (2003) Risk of febrile neutropenia among patients with intermediate-grade non-Hodgkin's lymphoma receiving CHOP chemotherapy. Leuk Lymphoma 44:2069-2076

17. Lyman GH, Dale DC, Friedberg J, Crawford J, Fisher RI (2004) Incidence and predictors of low chemotherapy dose-intensity in aggressive non-Hodgkin's lymphoma: a nationwide study. J Clin Oncol 22:4302-4311

18. Lyman GH, Lyman CH, Agboola O (2005) Risk models for predicting chemotherapy-induced neutropenia. Oncologist $10: 427-437$

19. Lyman GH, Kuderer NM, Poniewierksi MS, Crawford J, Wolff DA, Culakova E, Dale DC, Lyman GH, Kuderer NM, Poniewierksi MS, Crawford J, Wolff DA, Culakova E, Dale DC (2007) Factors associated with reductions in chemotherapy dose intensity: impact of clinical, sociodemographic and practice setting. J Clin Oncol 25: Abs 6550

20. Martin M, Lluch A, Segui MA, Ruiz A, Ramos M, Adrover E, Rodriguez-Lescure A, Grosse R, Calvo L, Fernandez-Chacon C, Roset M, Anton A, Isla D, Del Prado PM, Iglesias L, Zaluski J, Arcusa A, Lopez-Vega JM, Munoz M, Mel JR (2006) Toxicity and health-related quality of life in breast cancer patients receiving adjuvant docetaxel, doxorubicin, cyclophosphamide (TAC) or 5fluorouracil, doxorubicin and cyclophosphamide (FAC): impact of adding primary prophylactic granulocyte-colony stimulating factor to the TAC regimen. Ann Oncol 17:1205-1212

21. National Comprehensive Cancer Network Inc. (2007) NCCN clinical practice guidelines in oncology-Hodgkin disease/lymphoma V.1.2007. http://www.ncen.org/professionals/physician_gls/PDF/ hodgkins.pdf. Accessed 11 October, 2007

22. National Comprehensive Cancer Network Inc. (2007) NCCN clinical practice guidelines in oncology - myeloid growth factors V1.2007. http://www.nccn.org/professionals/physician_gls/PDF/ myeloid_growth.pdf. Accessed 11 October, 2007

23. NICE (2006) Docetaxol for the adjuvant treatment of early nodepositive breast cancer. NICE Technology Appraisal Guidance 109:1-21

24. Nijhuis CO, Kamps WA, Daenen SM, Gietema JA, van der Graaf WT, Groen HJ, Vellenga E, Ten Vergert EM, Vermeulen KM, de Vries-Hospers HG, de Bont ES (2005) Feasibility of withholding antibiotics in selected febrile neutropenic cancer patients. J Clin Oncol 20(23):7437-7444

25. Pettengell R, Gurney H, Radford JA, Deakin DP, James R, Wilkinson PM, Kane K, Bentley J, Crowther D (1992) Granulocyte colony-stimulating factor to prevent dose-limiting neutropenia in non-Hodgkin's lymphoma: a randomized controlled trial. Blood 80:1430-1436

26. Pfreundschuh M, Trumper L, Kloess M, Schmits R, Feller AC, Rube C, Rudolph C, Reiser M, Hossfeld DK, Eimermacher H, Hasenclever D, Schmitz N, Loeffler M, The German HighGrade Non-Hodgkin's Lymphoma Study G (2004) Two-weekly or 3-weekly CHOP chemotherapy with or without etoposide for the treatment of elderly patients with aggressive lymphomas: results of the NHL-B2 trial of the DSHNHL. Blood 104:634 641

27. Pfreundschuh M, Trumper L, Kloess M, Schmits R, Feller AC, Rudolph C, Reiser M, Hossfeld DK, Metzner B, Hasenclever D, Schmitz N, Glass B, Rube C, Loeffler M, The German HighGrade Non-Hodgkin's Lymphoma Study G (2004) Two-weekly or 3-weekly CHOP chemotherapy with or without etoposide for the treatment of young patients with good-prognosis (normal LDH) aggressive lymphomas: results of the NHL-B1 trial of the DSHNHL. Blood 104:626-633

28. Repetto L, Accettura C (2003) The importance of prophylactic management of chemotherapy-induced neutropenia. Anticancer Drugs 14:725-730 
29. Repetto L, Biganzoli L, Koehne CH, Luebbe AS, Soubeyran P, Tjan-Heijnen VC, Aapro MS (2003) EORTC Cancer in the Elderly Task Force guidelines for the use of colony-stimulating factors in elderly patients with cancer. Eur J Cancer 39:2264-2272

30. Schwenkglenks M, Jackisch C, Constenla M, Kerger JN, Paridaens R, Auerbach L, Bosly A, Pettengell R, Szucs TD, Leonard R (2006) Neutropenic event risk and impaired chemotherapy delivery in six European audits of breast cancer treatment. Support Care Cancer 14:901-909

31. Sehn LH, Connors JM (2005) Treatment of aggressive non-Hodgkin's lymphoma: a north American perspective. Oncology 19:26-34

32. Shayne M, Crawford J, Dale DC, Culakova E, Lyman GH (2006) Predictors of reduced dose intensity in patients with early-stage breast cancer receiving adjuvant chemotherapy. Breast Cancer Res Treat 100:255-262

33. Smith TJ, Khatcheressian J, Lyman GH, Ozer H, Armitage JO, Balducci L, Bennett CL, Cantor SB, Crawford J, Cross SJ, Demetri G, Desch CE, Pizzo PA, Schiffer CA, Schwartzberg L, Somerfield MR, Somlo G, Wade JC, Wade JL, Winn RJ, Wozniak AJ, Wolff AC (2006) 2006 update of recommendations for the use of white blood cell growth factors: an evidence-based clinical practice guideline. J Clin Oncol 24:3187-3205

34. Trudeau M, Charbonneau F, Gelmon K, Laing K, Latreille J, Mackey J, McLeod D, Pritchard K, Provencher L, Verma S (2005) Selection of adjuvant chemotherapy for treatment of node-positive breast cancer. Lancet Oncol 6:886-898 